\title{
Study on Complex Advertising and Price Competition Dual-Channel Supply Chain Models Considering the Overconfidence Manufacturer
}

\author{
Junhai Ma, Qiuxiang Li, and Binshuo Bao \\ College of Management and Economics, Tianjin University, Tianjin 300072, China \\ Correspondence should be addressed to Junhai Ma; mjhtju@aliyun.com
}

Received 5 February 2016; Accepted 22 June 2016

Academic Editor: Anna Pandolfi

Copyright (C) 2016 Junhai Ma et al. This is an open access article distributed under the Creative Commons Attribution License, which permits unrestricted use, distribution, and reproduction in any medium, provided the original work is properly cited.

\begin{abstract}
In order to explore how the manufacturers make decisions when two manufacturers compete for local advertising investment, we examine two noncooperative models (Stackelberg and Nash game) and propose a cost sharing contract to investigate channel competition of dual-channel supply chain. The dominant power between manufacturer and retailer and the effect of channel competition strategy on price are mainly discussed. In addition, dynamic system concepts are integrated into Stackelberg game model based on bounded rational mechanism. We analyze the local stability and find that the stability level of the dual-channel supply chains depends crucially on the price adjustment speed, the level of demand uncertainty, and the risk preference. The outcome shows that, under the master-slave game model, the profits of manufacturers are greater than that under decentralized decision-making mode, and the profits of retailers under master-slave game model are less than that under decentralized decision-making mode. The profits of manufacturers and retailers in the stable region are greater than that in unstable region. Finally, the delay feedback control method is utilized and effectively controls the chaotic behavior of dual-channel supply chain model. The results have theoretical and practical significance for the game models in terms of advertising and price competition.
\end{abstract}

\section{Introduction}

With the improvement of living standards and economic globalization, the types of products are becoming increasingly personalized and the competition among manufacturers and that among supply chains are becoming increasingly fierce. In recent years, supply chain management mainly focuses on the random demand of the market environment and the coordination between upstream and downstream enterprises. In this paper, we mainly consider two issues: (1) the dominant power between manufacturer and retailer and (2) the effect of channel competition strategy on price. In the absence of cooperation, supply chain participants arrive at their decisions independently and noncooperatively. This uncoordinated strategy may lead to channel inefficiency. One of the ways that can lead to a win-win outcome and channel coordination is to conduct vertical cooperative (Co) advertising programs.
Karray [1] compared equilibrium results of different dyad homogenous models and showed that the sequence of decisions has an impact on players' outcomes when each player (manufacturer or retailer) can set his/hers marketing expenditures and price simultaneously or sequentially, under the leadership of either manufacturer or retailer. He et al. [2] included the consumer price as an additional decision variable and assumed that demand is stochastic. De Giovanni [3] introduced the manufacturer's quality improvement effort while Zhang et al. [4] considered the consumer reference price as an extra decision instrument.

As competition within the market intensifies, many scholars become interested in the dual-channel supply chain. For example, Liu et al. [5] studied the leading manufacturers taking competition strategies in order to maintain their leading positions. Zhang et al. [6] studied the bilateral proprietary retailers such as those in the supply chain with double channels of alternative products and the influence 
of the channel position. Combining research literatures in advertising, Alaei et al. [7] discussed the case about how the manufacturer coordinates the channel in which two identical retailers compete in local advertising investment and examined four noncooperative models and cooperative games in order to investigate the possibility of channel coordination based on a cost sharing contract. Ahmadi Javid and Hoseinpour [8] investigated the coordination of cooperative advertising game model in a supply chain which has only one manufacturer and one retailer. The manufacturer agreed to share part of the total local advertising costs with the retailer.

Socially responsible firms are expected to use advertising judiciously, and limit advertising of "bad" products. Zhang et al. [9] studied the advertising initiative which was adopted by several major food manufacturers to limit the advertising of unhealthy food categories to children; in this paper, they examined the effectiveness of such advertising initiative in a leader-follower supply chain with one manufacturer and one retailer and found that the effectiveness of the advertising initiative critically depends on the leader's participation in the initiative.

Guo et al. [10] considered a firm's optimal sourcing decision from a mixed pool of suppliers who may or may not be socially responsible while balancing procurement cost increase and demand from socially conscious consumers. Giri and Sharma [11] studied a two-echelon supply chain with advertising-cost-dependent demand and developed two models. Computational results show that it is always profitable for the manufacturer to adopt different wholesale pricing strategies to deal with the retailers.

Some scholars studied on cooperative advertising present dynamic models and differential games for long-term, multiperiod relationships between manufacturers and retailers (e.g., see [12-14]). Others focus on a static, single-period relationship involving cooperative advertising (e.g., see [1518]). Chutani and Sethi [19] studied a dynamic durable goods duopoly in a supply chain with a manufacturer and two independent and competing retailers and obtained the feedback equilibrium policies for the manufacturer and the retailers in explicit form for a linear demand formulation. $\mathrm{Ma}$ and Li [20] studied the dynamic complexity of a riskaverse supply chain with two manufacturers and a common retailer under uncertain demand and found the influence of parameters on the price and stable region of the system.

Some scholars studied the dual-channel supply chain: Li et al. [21] investigated a dual-channel supply chain with a risk-neutral manufacturer and a risk-averse retailer. There is only one perishable product with price-dependent stochastic demand. Zhang et al. [22] utilized a contract with a wholesale price and a lump sum fee to coordinate a dual-channel supply chain under the cases of demand disruptions and production cost disruptions. Panda et al. [23] explored pricing and replenishment policies for a high-tech product in a dualchannel supply chain. Li et al. [24] analyzed the dynamics of heterogeneous retailers in a dual-channel energy supply chain with the three-dimensional dynamic system. We found that there is a heated price competition between the retail and online channel. Besides, product compatibility has a significant impact on the pricing policy.

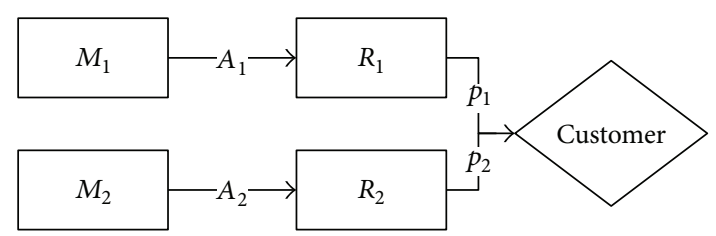

FIGURE 1: Dual-channel supply chain system.

Ma and Guo [25] probed into the complex dynamics of a bivariate game considering the real competitions in service market which contains two important factors (price and service) with building a dynamical price and service game model.

Sun and Ma [26] concentrated on a Bertrand Triopoly team-game model whereby two firms with bounded rational expectations make up a cooperative team and allocate common profits proportionate to their marketing strength.

According to the above literature, the study on the dual-channel supply chain dynamic advertising strategy is needed. In this paper, we present both static and dynamic models of cooperative advertising in a dual-channel supply chain system which consists of two manufacturers and two retailers. Regarding the different results between our study and previous studies, our analysis is of great significance.

The paper is organized as follows. To begin with, the assumptions and models are presented in Section 2. Section 3 is mainly the analysis of the models. In Section 4, the chaos control of the model is studied. Section 5 is the conclusion.

\section{Assumptions and Modeling}

The study of this paper focuses on a dual-channel supply chain system composed of two manufacturers and two retailers, as shown in Figure 1. First of all, to gain more profit for their own, the two manufacturers make advertising decisions according to manufacturer's decision making information; the retailers determine the retail price of each product. Retailers share the manufacturer's advertising costs.

2.1. Assumptions. Some assumptions are made according to the marketing scenario and its practical operation:

(1) Two manufacturers have certain alternative products, and through the proprietary retailers to sell in the same market, manufacturer is the leader and the competition is in advertising; it accords with Bertrand competition model.

(2) Two contracts manufacturers and retailers signed on the cost are according to actual conditions; namely, retailers undertake part of the manufacturer's advertising costs. Retailers make decisions for price competition according to manufacturer's advertising levels.

(3) Two manufacturers cannot fully grasp the market information and take the rationality-limited decision method in decision making. 
(4) For convenient calculation, we assume that the two manufacturers' production cost is zero; retailer's operations and sales costs are zero.

(5) Customer demand is uncertain, manufacturers have overconfidence behavior, and retailers have risk avoiding behavior.

2.2. Modeling. This section mainly considers two game models:

(1) Decentralized decision making model: manufacturers and retailers intend to maximize the profit of their decision at the same time, represented by $(D)$.

(2) Stackelberg game: manufacturers make advertising decisions according to their mastery of the information firstly. Retailers make decisions according to manufacturer's price information, represented by $(S)$.

Based on above literature, combined with the actual market competition situation, formula (1) gives demand functions of two products:

$$
\begin{aligned}
& D_{1}=a_{1}-\theta p_{1}+b p_{2}+\left(\alpha+\delta_{1}\right) \sqrt{A_{1}}-\beta \sqrt{A_{2}}, \\
& D_{2}=a_{2}-\theta p_{2}+b p_{1}+\left(\alpha+\delta_{2}\right) \sqrt{A_{2}}-\beta \sqrt{A_{1}},
\end{aligned}
$$

where $a_{1}$ and $a_{2}$ are the basis market demand of products 1 and $2, \theta$ is the price elasticity of the product, $b$ is the cross price elasticity of the product, $\alpha$ is the sensitivity of the demand for advertising products, $\delta_{i} \geq 0$ means manufacturer's overconfidence coefficient, the greater $\delta_{i}$ is, the higher advertising effect of the advertising is, and $\beta$ is the cross elasticity of the advertising.

At present, advertising is a big challenge for manufacturers providing new products; advertising directly affects the market demand of the product. The major problem in the study of this section is that in the process of decision making of manufacturers and retailers, which is optimal, with decentralized decision making or sequential decision making.

2.2.1. Decentralized Decision Making Model. In reality, the manufacturers and retailers make decisions to maximize their own profits at the same time; in this case, the manufacturers and retailers adopt decentralized pricing strategy, manufacturers have overconfidence behavior, and retailers have risk avoidance behavior. Customer's basic demand for the product is uncertain; namely, $a_{i}=\overline{a_{i}}+\varepsilon_{i}, i=1,2, \varepsilon_{i}$ follows normal distribution, the mean is zero, and the variance is $\sigma_{i}, i=1,2$. The expected profit function of manufacturers and retailers in dual-channel supply chain can be expressed as follows:

$$
\begin{aligned}
& \pi_{M_{1}}^{D}=w_{1} D_{1}-\phi_{1} A_{1}^{D}, \\
& \pi_{M_{2}}^{D}=w_{2} D_{2}-\phi_{2} A_{2}^{D},
\end{aligned}
$$

$$
\begin{aligned}
& \pi_{R_{1}}^{D}=\left(p_{1}^{D}-w_{1}\right) D_{1}-\left(1-\phi_{1}\right) A_{1}^{D}-\frac{\left(p_{1}^{D}-w_{1}\right)^{2} \sigma_{1}^{2}}{2 R_{R_{1}}}, \\
& \pi_{R_{2}}^{D}=\left(p_{2}^{D}-w_{2}\right) D_{2}-\left(1-\phi_{2}\right) A_{2}^{D}-\frac{\left(p_{2}^{D}-w_{2}\right)^{2} \sigma_{2}^{2}}{2 R_{R_{2}}},
\end{aligned}
$$

where $\phi_{i}, i=1,2$ is advertising cost sharing coefficient and $R_{R_{i}}, i=1,2$ is levels of risk aversion.

We can get the marginal profits of manufacturers and retailers:

$$
\begin{aligned}
\frac{\partial \pi_{1}^{D}}{\partial A_{1}^{D}}= & \frac{w_{1}\left(\alpha+\delta_{1}\right)}{2 \sqrt{A_{1}^{D}}}-\phi_{1}, \\
\frac{\partial \pi_{1}^{D}}{\partial p_{1}^{D}}= & a_{1}-\beta \sqrt{A_{2}^{D}}-2 \theta p_{1}^{D}+b p_{2}^{D}+\theta w_{1} \\
& +\sqrt{A_{1}^{D}}\left(\alpha+\delta_{1}\right)-\frac{\left(p_{1}^{D}-w_{1}\right) \sigma_{1}^{2}}{R_{R_{1}}}, \\
\frac{\partial \pi_{2}^{D}}{\partial A_{2}^{D}}= & \frac{w_{2}\left(\alpha+\delta_{2}\right)}{2 \sqrt{A_{2}^{D}}}-\phi_{2}, \\
\frac{\partial \pi_{2}^{D}}{\partial p_{2}^{D}}= & a_{2}-\beta \sqrt{A_{1}^{D}}+b p_{1}^{D}-2 \theta p_{2}^{D}+\theta w_{2} \\
& +\sqrt{A_{2}^{D}}\left(\alpha+\delta_{2}\right)-\frac{\left(p_{2}^{D}-w_{2}\right) \sigma_{2}^{2}}{R_{R_{2}}} .
\end{aligned}
$$

We get the equilibrium advertising and product prices of the manufacturers and retailers:

$$
\begin{aligned}
& A_{1}^{D}=\left(\frac{w_{1}\left(\alpha+\delta_{1}\right)}{2 \phi_{1}}\right)^{2}, \\
& A_{2}^{D}=\left(\frac{w_{2}\left(\alpha+\delta_{2}\right)}{2 \phi_{2}}\right)^{2}, \\
& p_{1}^{D} \\
& \quad=\frac{b g_{2}+\left(2 \theta-\sigma_{2}^{2} / R_{R_{2}}\right) g_{1}}{\sigma_{1}^{2} \sigma_{2}^{2} / R_{R_{1}} R_{R_{2}}+2 \theta \sigma_{1}^{2} / R_{R_{1}}+2 \theta \sigma_{2}^{2} / R_{R_{2}}+4 \theta^{2}-b^{2}}, \\
& p_{2}^{D} \\
& \quad=\frac{b g_{1}+\left(2 \theta-\sigma_{1}^{2} / R_{R_{1}}\right) g_{2}}{\sigma_{1}^{2} \sigma_{2}^{2} / R_{R_{1}} R_{R_{2}}+2 \theta \sigma_{1}^{2} / R_{R_{1}}+2 \theta \sigma_{2}^{2} / R_{R_{2}}+4 \theta^{2}-b^{2}},
\end{aligned}
$$

where $g_{1}=a_{1}+\theta w_{1}-\beta w_{2}\left(\alpha+\delta_{2}\right) / 2 \phi_{2}+w_{1}\left(\alpha+\delta_{1}\right)^{2} / 2 \phi_{1}+$ $w_{1} \sigma_{1}^{2} / R_{R_{1}}, g_{2}=a_{2}+\theta w_{2}-\beta w_{1}\left(\alpha+\delta_{1}\right) / 2 \phi_{1}+w_{2}\left(\alpha+\delta_{2}\right)^{2} / 2 \phi_{2}+$ $w_{2} \sigma_{2}^{2} / R_{R_{2}}$.

2.2.2. Stackelberg Game Model. Two manufacturers firstly determine their advertising investment; retailers determine 
the retail price of products according to manufacturer's decision information. By the backward method, we can get the marginal profits of retailers:

$$
\begin{gathered}
a_{1}-\theta p_{1}^{S}+b p_{2}^{S}+\sqrt{A_{1}^{S}}\left(\alpha+\delta_{1}\right)-\beta \sqrt{A_{2}^{S}}-\theta\left(p_{1}^{S}-w_{1}\right) \\
-\frac{\left(p_{1}^{S}-w_{1}\right) \sigma_{1}^{2}}{R_{R_{1}}}=0,
\end{gathered}
$$

$$
\begin{gathered}
a_{2}-\theta p_{2}^{S}+b p_{1}^{S}+\sqrt{A_{2}^{S}}\left(\alpha+\delta_{2}\right)-\beta \sqrt{A_{1}^{S}}-\theta\left(p_{2}^{S}-w_{2}\right) \\
-\frac{\left(p_{2}^{S}-w_{2}\right) \sigma_{2}^{2}}{R_{R_{2}}}=0 .
\end{gathered}
$$

We can get the retailer's optimal reaction function:

$p_{1}^{S}$

$=\frac{\left(-\sqrt{A_{2}^{S}} \beta+a_{1}+\theta w_{1}+\sqrt{A_{1}^{S}}\left(\alpha+\delta_{1}\right)+w_{1} \sigma_{1}^{2} / R_{R_{1}}\right)\left(-2 \theta-\sigma_{2}^{2} / R_{R_{2}}\right)-b\left(a_{2}-\sqrt{A_{1}^{S}} \beta+\theta w_{2}+\sqrt{A_{2}^{S}}\left(\alpha+\delta_{2}\right)+w_{2} \sigma_{2}^{2} / R_{R_{2}}\right)}{b^{2}-\left(-2 \theta-\sigma_{1}^{2} / R_{R_{1}}\right)\left(-2 \theta-\sigma_{2}^{2} / R_{R_{2}}\right)}$

$p_{2}^{S}$

$$
=\frac{\left(-\sqrt{A_{1}^{S}} \beta+a_{2}+\theta w_{2}+\sqrt{A_{2}^{S}}\left(\alpha+\delta_{2}\right)+w_{2} \sigma_{2}^{2} / R_{R_{2}}\right)\left(-2 \theta-\sigma_{2}^{2} / R_{R_{2}}\right)-b\left(a_{1}-\sqrt{A_{2}^{S}} \beta+\theta w_{1}+\sqrt{A_{1}^{S}}\left(\alpha+\delta_{1}\right)+w_{1} \sigma_{1}^{2} / R_{R_{1}}\right)}{b^{2}-\left(-2 \theta-\sigma_{1}^{2} / R_{R_{1}}\right)\left(-2 \theta-\sigma_{2}^{2} / R_{R_{2}}\right)} .
$$

Make the first derivative on advertising of the manufacturer's profit functions:

$$
\begin{aligned}
& \frac{w_{1}\left(\theta R_{R_{1}}+\sigma_{1}^{2}\right)\left[R_{R_{2}}\left(-b \beta+2 \alpha \theta+2 \theta \delta_{1}\right)+\sigma_{2}^{2}\left(\alpha+\delta_{1}\right)\right]}{2 \sqrt{A_{1}^{S}} \sigma_{1}^{2}\left(2 \theta R_{R_{2}}+\sigma_{2}^{2}\right)+2 \sqrt{A_{1}} R_{R_{1}}\left[2 \theta \sigma_{2}^{2}-R_{R_{2}}\left(b^{2}-4 \theta^{2}\right)\right]} \\
& \quad-\phi_{1}=0, \\
& \frac{w_{2}\left(\theta R_{R_{2}}+\sigma_{2}^{2}\right)\left[R_{R_{1}}\left(b \beta-2 \alpha \theta-2 \theta \delta_{2}\right)-\sigma_{1}^{2}\left(\alpha+\delta_{2}\right)\right]}{2 \sqrt{A_{2}^{S}}\left(-\sigma_{1}^{2}\left(2 \theta R_{R_{2}}+\sigma_{2}^{2}\right)+R_{R_{1}}\left(\left(b^{2}-4 \theta^{2}\right) R_{R_{2}}-2 \theta \sigma_{2}^{2}\right)\right)} \\
& -\phi_{2}=0 .
\end{aligned}
$$

Thus, we can get the optimal reaction function of manufacturers as follows:

$$
\begin{aligned}
& \sqrt{A_{1}^{S}} \\
& =-\frac{w_{1}\left(\theta R_{R_{1}}+\sigma_{1}^{2}\right)\left(R_{R_{2}}\left(-b \beta+2 \alpha \theta+2 \theta \delta_{1}\right)+\left(\alpha+\delta_{1}\right) \sigma_{2}^{2}\right)}{2 \phi_{1}\left(-\sigma_{1}^{2}\left(2 \theta R_{R_{2}}+\sigma_{2}^{2}\right)+R_{R_{1}}\left(\left(b^{2}-4 \theta^{2}\right) R_{R_{2}}-2 \theta \sigma_{2}^{2}\right)\right)}, \\
& \sqrt{A_{2}^{S}} \\
& =\frac{w_{2}\left(R_{R_{1}}\left(b \beta-2 \alpha \theta-2 \theta \delta_{2}\right)-\left(\alpha+\delta_{2}\right) \sigma_{1}^{2}\right)\left(\theta R_{R_{2}}+\sigma_{2}^{2}\right)}{2 \phi_{2}\left(-\sigma_{1}^{2}\left(2 \theta R_{R_{2}}+\sigma_{2}^{2}\right)+R_{R_{1}}\left(\left(b^{2}-4 \theta^{2}\right) R_{R_{2}}-2 \theta \sigma_{2}^{2}\right)\right)} .
\end{aligned}
$$

Substitute formula (8) into formula (6); we get the retail prices of products.

\section{Analysis}

3.1. The Simulation Experiment. As it is very difficult to study the influence of parameters on the decision variables through analytical analysis method, hence, we study the effect of variable and parameters on the profits of manufacturers and retailers by the experimental method. According to the actual reality of competition situation, set $a_{1}=10, a_{2}=10, \theta=$ $0.3, b=0.2, a=0.5, \delta_{1}=0.2, \delta_{2}=0.2, \beta=0.2, \phi_{1}=$ $0.9, \phi_{2}=0.8, \sigma_{1}=0.5, \sigma_{2}=0.5, R_{R_{1}}=60, R_{R_{2}}=$ $60, w_{1}=10$, and $w_{2}=8$.

Tables 1, 2, 3, and 4, respectively, illustrate the change of advertising investment price and profit with different $\phi_{1}$ when $\delta_{1}=0.2$ and $\delta_{1}=0.6$. By comparing the four tables, we find that under the two kinds of decision models, with the increase of overconfidence level, the manufacturers' advertising level and the retail price increase; under decentralized decision making mode, advertising level and the retail price of products are greater than that with master-slave decisions, so under the master-slave decision making mode, the customer can get more surplus value. From Tables 3 and 4, the manufacturer's profit in master-slave decision making mode is greater than the manufacturer's profit in decentralized decision making mode, and the profits of retailers in master-slave decision making mode are less than that in decentralized decision making mode. Therefore, manufacturers and customers in the master-slave game can get more profit and utility. As retailers share the advertising costs, factors such as advertising level, their profits, and retail prices all increase, showing that the retailers sharing the advertising costs make promotion for advertising level. Table 5 shows that, as the $\phi_{1}$ decreases, the extent of increase in profit of manufacturers in master-slave decision making mode is greater than that in the decentralized decision making mode, and the extent of increase in profit of retailers in master-slave decision making mode is less than that in the decentralized decision making mode. From the above analysis, it can be seen that the dominant manufacturers have a first-mover advantage that they can obtain the biggest 
TABLE 1: The changes of advertising and the retail price $\left(\delta_{1}=0.2\right)$.

\begin{tabular}{ccccccccc}
\hline & \multicolumn{3}{c}{$\begin{array}{c}\text { Master-slave } \\
\text { decision }\end{array} \phi_{1}$} & \multicolumn{4}{c}{$\begin{array}{c}\text { Decentralized decision } \\
\text { making }\end{array}$} \\
& $A_{1}$ & $A_{2}$ & $p_{1}$ & $p_{2}$ & $A_{1}$ & $A_{2}$ & $p_{1}$ & $p_{2}$ \\
\hline 0.9 & 4.37 & 3.54 & 32.37 & 31.33 & 15.12 & 12.25 & 34.4 & 33.17 \\
0.8 & 5.52 & 3.54 & 32.66 & 31.34 & 19.14 & 12.25 & 34.94 & 33.19 \\
0.7 & 7.22 & 3.54 & 33.03 & 31.35 & 25 & 12.25 & 35.62 & 33.21 \\
0.6 & 9.82 & 3.54 & 33.52 & 31.37 & 34.03 & 12.25 & 36.54 & 33.23 \\
0.5 & 14.14 & 3.54 & 34.21 & 31.39 & 49 & 12.25 & 37.82 & 33.27 \\
\hline
\end{tabular}

TABLE 2: The changes of advertising and the retail price $\left(\delta_{1}=0.6\right)$.

\begin{tabular}{ccccccccc}
\hline & \multicolumn{3}{c}{$\begin{array}{c}\text { Master-slave } \\
\phi_{1}\end{array}$} & \multicolumn{3}{c}{ decision } & \multicolumn{4}{c}{$\begin{array}{c}\text { Decentralized decision } \\
\text { making }\end{array}$} \\
& $A_{1}$ & $A_{2}$ & $p_{1}$ & $p_{2}$ & $A_{1}$ & $A_{2}$ & $p_{1}$ & $p_{2}$ \\
\hline 0.9 & 11.56 & 3.54 & 36.16 & 32.11 & 37.35 & 12.25 & 41.07 & 34.56 \\
0.8 & 14.63 & 3.54 & 36.92 & 32.21 & 47.27 & 12.25 & 42.43 & 34.75 \\
0.7 & 19.11 & 3.54 & 37.9 & 32.35 & 61.73 & 12.25 & 44.19 & 34.99 \\
0.6 & 26 & 3.54 & 39.2 & 32.52 & 84.02 & 12.25 & 46.54 & 35.31 \\
0.5 & 37.45 & 3.54 & 41.03 & 32.78 & 121 & 12.25 & 49.82 & 35.76 \\
\hline
\end{tabular}

TABLE 3: Profits of manufacturers and retailers $\left(\delta_{1}=0.2\right)$.

\begin{tabular}{cccccccccc}
\hline \multicolumn{4}{c}{ Master-slave decision } & \multicolumn{4}{c}{$\begin{array}{c}\text { Decentralized decision } \\
\text { making }\end{array}$} \\
& $\pi_{M_{1}}$ & $\pi_{M_{2}}$ & $\pi_{R_{1}}$ & $\pi_{R_{2}}$ & $\pi_{M_{1}}$ & $\pi_{M_{2}}$ & $\pi_{R_{1}}$ & $\pi_{R_{2}}$ \\
\hline 0.9 & 72.5 & 60.95 & 160.09 & 173.97 & 69.76 & 59 & 189.5 & 200.84 \\
0.8 & 72.99 & 60.97 & 163.58 & 174.09 & 69.88 & 59.05 & 195.65 & 201.09 \\
0.7 & 73.62 & 61 & 167.93 & 174.25 & 70.05 & 59.1 & 203.14 & 201.41 \\
0.6 & 74.46 & 61.04 & 173.53 & 174.46 & 70.16 & 59.17 & 212.38 & 201.83 \\
0.5 & 75.64 & 61.09 & 180.95 & 174.75 & 70.57 & 59.27 & 223.89 & 202.43 \\
\hline
\end{tabular}

TABle 4: Profits of manufacturers and retailers $\left(\delta_{1}=0.6\right)$.

\begin{tabular}{ccccccccc}
\hline & \multicolumn{4}{c}{ Master-slave decision } & \multicolumn{4}{c}{$\begin{array}{c}\text { Decentralized decision } \\
\text { making }\end{array}$} \\
& $\pi_{M_{1}}$ & $\pi_{M_{2}}$ & $\pi_{R_{1}}$ & $\pi_{R_{2}}$ & $\pi_{M_{1}}$ & $\pi_{M_{2}}$ & $\pi_{R_{1}}$ & $\pi_{R_{2}}$ \\
\hline 0.9 & 78.97 & 63.06 & 218.38 & 185.73 & 72.53 & 62.79 & 305.89 & 223.83 \\
0.8 & 80.27 & 63.35 & 229.57 & 187.35 & 73 & 63.3 & 328.05 & 227.05 \\
0.7 & 81.94 & 63.72 & 243.98 & 189.45 & 73.61 & 63.97 & 356.58 & 231.23 \\
0.6 & 84.17 & 64.21 & 263.21 & 192.27 & 74.42 & 64.85 & 394.72 & 236.85 \\
0.5 & 87.3 & 64.89 & 290.19 & 196.25 & 75.56 & 66.08 & 448.28 & 244.84 \\
\hline
\end{tabular}

benefit by forming a small advertising, which has great influence on the cost sharing proportion of advertising investment and profits of manufacturers and retailers; the manufacturers determine the cost share proportion of manufacturers and retailers according to the customer acceptance of the product price.

Further, the differentiation of retail price is negligible to the customers as the purchase and the demand are mainly
TABLE 5: Profit variations of manufacturers and retailers with different overconfidence level.

\begin{tabular}{|c|c|c|c|c|c|c|c|c|}
\hline \multirow[t]{2}{*}{$\phi_{1}$} & \multicolumn{4}{|c|}{$\begin{array}{l}\text { Master-slave } \\
\text { decision }\end{array}$} & \multicolumn{4}{|c|}{$\begin{array}{l}\text { Decentralized decision } \\
\text { making }\end{array}$} \\
\hline & $\pi_{M_{1}}$ & $\pi_{M_{2}}$ & $\pi_{R_{1}}$ & $\pi_{R_{2}}$ & $\pi_{M_{1}}$ & $\pi_{M_{2}}$ & $\pi_{R_{1}}$ & $\pi_{R_{2}}$ \\
\hline 0.9 & 6.47 & 2.11 & 58.29 & 11.76 & 2.77 & 3.79 & 116.39 & 22.99 \\
\hline 0.8 & 7.28 & 2.38 & 65.99 & 13.26 & 3.12 & 4 & 132.4 & 25.96 \\
\hline 0.7 & 8.32 & 2.71 & 76.05 & 15.2 & 3.56 & 4.8 & 153.44 & 29.82 \\
\hline 0.6 & 9.71 & 3.17 & 89.68 & 17.81 & 4.26 & 5.3 & 182.34 & 35.02 \\
\hline 0.5 & 11.66 & 3.8 & 109.24 & 21.5 & 4.99 & 6.81 & 224.39 & 42.41 \\
\hline
\end{tabular}

influenced by the advertising costs incurred by the two competing retailers. For each retailer, the demand increases in his own advertising while it decreases in the advertising done by his rival.

We can also draw the Contour Plot to show the influence of the parameters $\delta_{1}$ and $\phi_{1}$ on the decision variables and their profits.

From Figure 2 we can see that when they make masterslave decisions, the parameters $\delta_{1}$ and $\phi_{1}$ will have a negative influence on the optimal prices $p_{1}$ and $p_{2}$. As $\delta_{1}$ increases, $p_{1}$ will increase, which means that the retailer will offer a higher price if it is more confident. At the same time, it will reduce its competitor's price. The more the retailer undertakes shared advertising cost, the higher its price is. The retailer will shift its advertising cost to the consumers. For the manufacturers, if they have to undertake more advertising cost, they will make less investment in advertise.

From Figure 3, we can see that a higher $\delta_{1}$ and a lower $\phi_{1}$ will lead to higher profits for the four firms. When the manufacturers are overconfident, they can get more profit, as well as the other firms. When the retailer undertakes more shared advertising cost, they can earn more benefits and make other firms earn more at the same time.

According to Figure 4 we can find that when making decentralized decisions, the parameters $\delta_{1}$ and $\phi_{1}$ also have a negative influence on the two optimal prices. $p_{1}$ gets smaller and smaller with the increase of $\delta_{1}$. We can come to the conclusion that the more confident the retailer becomes, the lower the retailer prices will be. Besides, more confidence will lead to higher retail price of the competitor, and lower advertising cost will reduce the retailer price.

From Figure 5, we can see that a higher $\delta_{1}$ and a lower $\phi_{1}$ will lead to higher profits for the four firms, which is similar to the circumstance in Figure 3. With the increase of $\delta_{1}$, more and more profits will be obtained by all of the four firms, and more advertising cost will bring more benefits to the retailers.

3.2. Stability Analysis. In the real market competition, manufacturers cannot grasp the perfect market information; the manufacturer cannot adjust advertising into the equilibrium position at once. According to the above analysis, the advertising game process is a complex repeated dynamic evolution. In this section we develop a Stackelberg game model in 

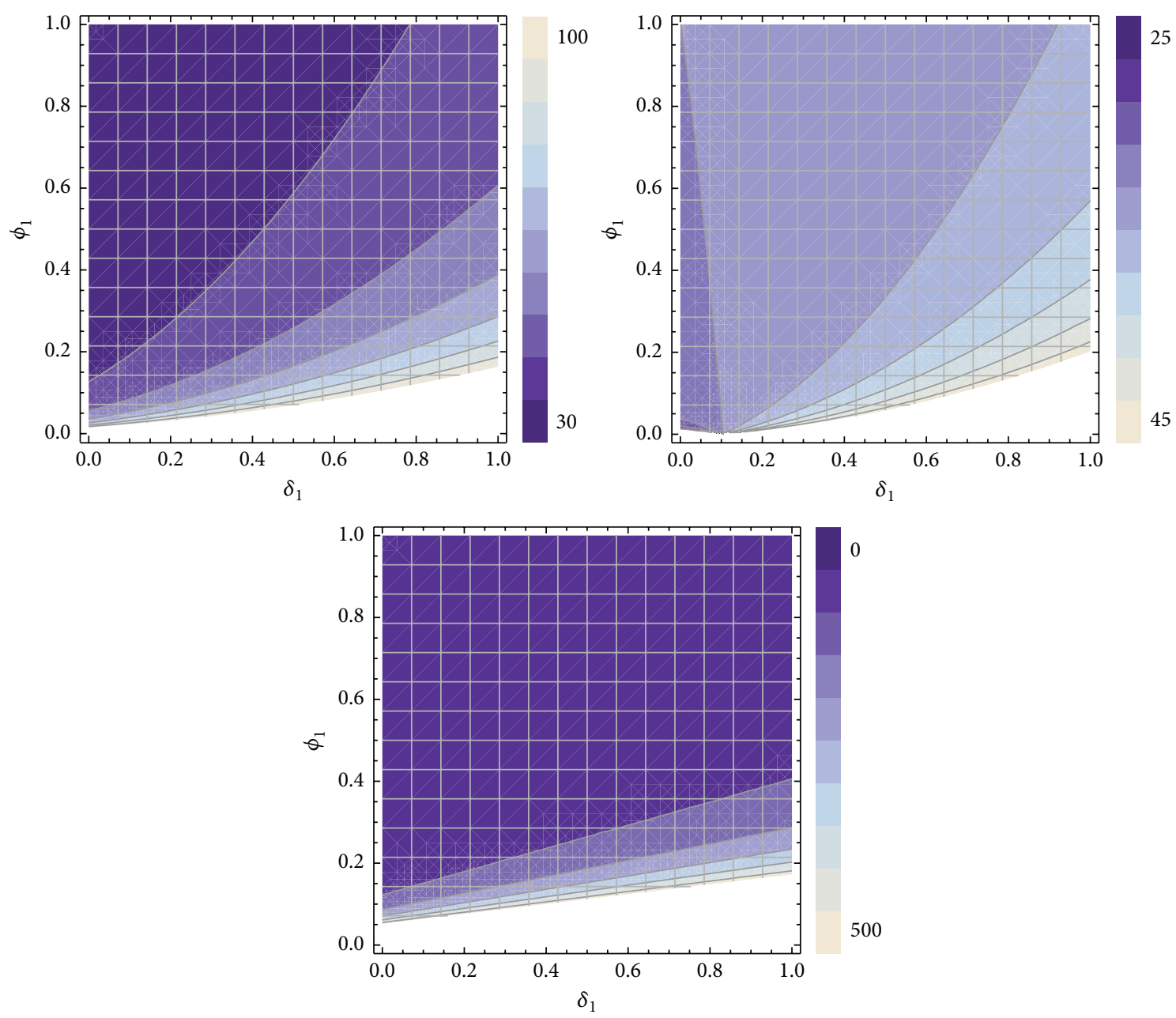

FIGURE 2: The influence of parameters $\delta_{1}$ and $\phi_{1}$ on $p_{1}, p_{2}$, and $A_{1}$ in master-slave decision.

a dual-channel supply chain; the dynamic game model is as follows:

$$
A_{i}(t+1)=A_{i}(t)+k_{i} A_{i}(t) \frac{\partial \pi_{M_{i}}\left(A_{1}, A_{2}\right)}{\partial A_{i}},
$$

where $k_{i}$ represents manufacturer's speed of adjusting advertising in dual-channel supply chain; if manufacturer's marginal profit is positive in $t$ period, the manufacturer will increase advertising level in $t+1$ period. On the other hand, if the marginal profit of the manufacturer is negative in $t$ period, the manufacturer will reduce advertising level in $t+1$ period.

According to the previous analysis, we can get the discrete dynamic system model of manufacturer advertising in dualchannel supply chain:

$$
\begin{aligned}
& A_{1}(t+1)=A_{1}(t)+k_{1} A_{1}(t)\left(\frac{w_{1}\left(\theta R_{R_{1}}+\sigma_{1}^{2}\right)\left[R_{R_{2}}\left(-b \beta+2 \alpha \theta+2 \theta \delta_{1}\right)+\sigma_{2}^{2}\left(\alpha+\delta_{1}\right)\right]}{2 \sqrt{A_{1}(t)}\left(\sigma_{1}^{2}\left(2 \theta R_{R_{2}}+\sigma_{2}^{2}\right)+R_{R_{1}}\left(2 \theta \sigma_{2}^{2}-R_{R_{2}}\left(b^{2}-4 \theta^{2}\right)\right)\right)}-\phi_{1}\right), \\
& A_{2}(t+1)=A_{2}(t)+k_{2} A_{2}(t)\left(\frac{w_{2}\left(\theta R_{R_{2}}+\sigma_{2}^{2}\right)\left[R_{R_{1}}\left(b \beta-2 \alpha \theta-2 \theta \delta_{2}\right)-\sigma_{1}^{2}\left(\alpha+\delta_{2}\right)\right]}{2 \sqrt{A_{2}(t)}\left(-\sigma_{1}^{2}\left(2 \theta R_{R_{2}}+\sigma_{2}^{2}\right)+R_{R_{1}}\left(\left(b^{2}-4 \theta^{2}\right) R_{R_{2}}-2 \theta \sigma_{2}^{2}\right)\right)}-\phi_{2}\right) .
\end{aligned}
$$



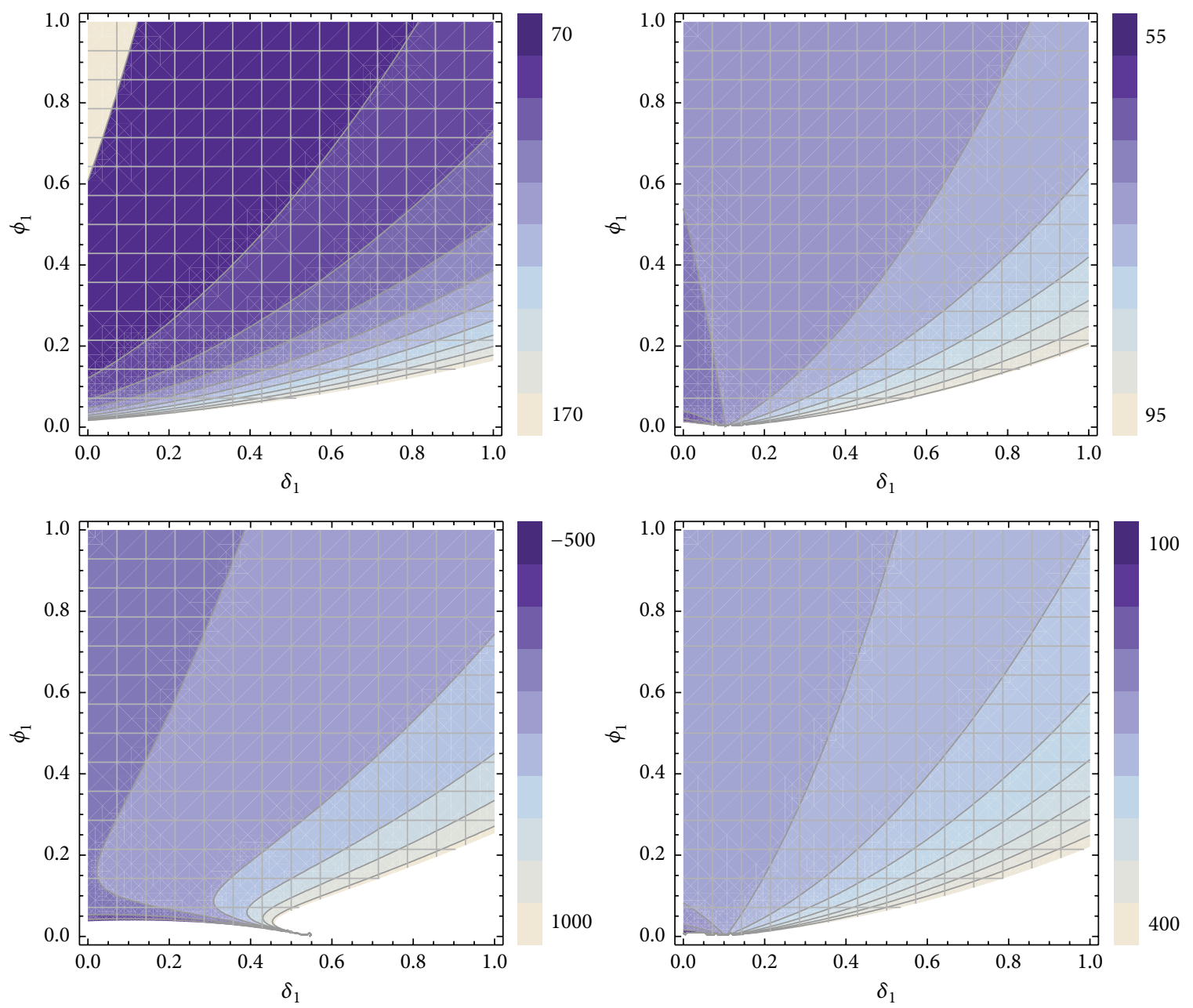

FIGURE 3: The influence of parameters $\delta_{1}$ and $\phi_{1}$ on $\pi_{M_{1}}, \pi_{M_{2}}, \pi_{R_{1}}$, and $\pi_{R_{2}}$ in master-slave decision.

3.2.1. The Equilibrium Point of the System. Based on the definition of the differences, we can get the expression of the equilibrium point of system (10):

$$
\begin{aligned}
& A_{1} \\
& =\frac{w_{1}^{2}\left(R_{R_{1}} \theta+\sigma_{1}^{2}\right)^{2}\left(b R_{R_{2}} \beta-\left(\alpha+\delta_{1}\right)\left(2 R_{R_{2}} \theta+\sigma_{2}^{2}\right)\right)^{2}}{4\left(b^{2} R_{R_{1}} R_{R_{2}}-\left(2 R_{R_{1}} \theta+\sigma_{1}^{2}\right)\left(2 R_{R_{2}} \theta+\sigma_{2}^{2}\right)\right)^{2} \phi_{1}^{2}},
\end{aligned}
$$

$A_{2}$

$$
=\frac{w_{2}^{2}\left(b R_{R_{1}} \beta-\left(\alpha+\delta_{2}\right)\left(2 R_{R_{1}} \theta+\sigma_{1}^{2}\right)\right)^{2}\left(R_{R_{2}} \theta+\sigma_{2}^{2}\right)^{2}}{4\left(b^{2} R_{R_{1}} R_{R_{2}}-\left(2 R_{R_{1}} \theta+\sigma_{1}^{2}\right)\left(2 R_{R_{2}} \theta+\sigma_{2}^{2}\right)\right)^{2} \phi_{2}^{2}} .
$$

Based on the reaction function of $p_{1}$ and $p_{2}$, we can get the expression of prices $p_{1}$ and $p_{2}$. Set $a_{1}=10, a_{2}=10, \theta=$ $0.3, b=0.2, a=0.5, \delta_{1}=0.2, \delta_{2}=0.2, \beta=0.2, \phi_{1}=$ $0.9, \phi_{2}=0.8, \sigma_{1}=0.5, \sigma_{2}=0.5, R_{R_{1}}=60, R_{R_{2}}=$ $60, w_{1}=10$, and $w_{2}=8$. Using formula (11), we get four equilibrium systems, respectively: $E_{1}=(0,0,30.01,29.2)$, $E_{2}=(0,3.536,30.07,31.27), E_{3}=(4.365,0,32.31,29.26)$, and $E_{4}=(4.365,3.536,32.37,31.33)$. Obviously $E_{1}, E_{2}, E_{3}$ are boundary bounded equilibrium; $E_{4}$ is the only Nash equilibrium of system (10).

3.2.2. Stability Analysis. In order to analyze the stability of the equilibrium, we firstly calculate the Jacobian matrix system (10):

$$
J(E)=\left(\begin{array}{cc}
1-k_{1} \phi_{1}+k_{1} w_{1} H_{1} & 0 \\
0 & 1-k_{2} \phi_{2}+k_{2} w_{2} H_{2}
\end{array}\right),
$$

where

$$
\begin{aligned}
H_{1} & =\frac{a+\delta_{1}}{4 \sqrt{A_{1}}} \\
& -\frac{\left(a+\delta_{1}\right)\left[b^{2}+\theta\left(-2 \theta-\sigma_{2}^{2} / R_{R_{2}}\right)\right]+b \beta\left(\theta-2 \theta-\sigma_{1}^{2} / R_{R_{1}}\right)}{4 \sqrt{A_{1}}\left[b^{2}-\left(-2 \theta-\sigma_{1}^{2} / R_{R_{1}}\right)\left(-2 \theta-\sigma_{2}^{2} / R_{R_{2}}\right)\right]},
\end{aligned}
$$



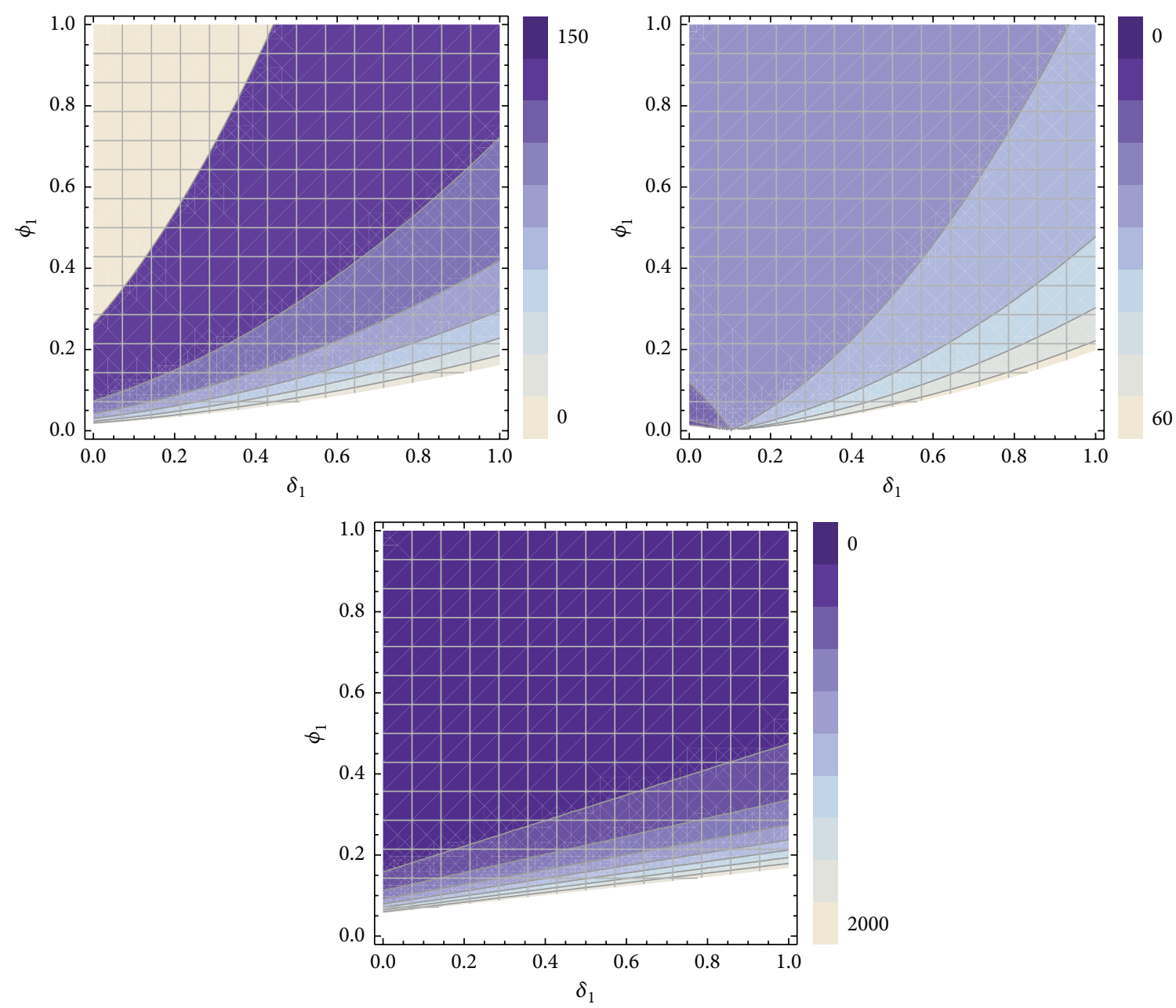

FIgURE 4: The influence of parameters $\delta_{1}$ and $\phi_{1}$ on $p_{1}, p_{2}$, and $A_{1}$ in decentralized decision making.

$$
\begin{aligned}
H_{2} & =\frac{a+\delta_{2}}{4 \sqrt{A_{2}}} \\
& -\frac{\left(a+\delta_{2}\right)\left[b^{2}+\theta\left(-2 \theta-\sigma_{1}^{2} / R_{R_{1}}\right)\right]+b \beta\left(\theta-2 \theta-\sigma_{2}^{2} / R_{R_{2}}\right)}{4 \sqrt{A_{2}}\left[b^{2}-\left(-2 \theta-\sigma_{1}^{2} / R_{R_{1}}\right)\left(-2 \theta-\sigma_{2}^{2} / R_{R_{2}}\right)\right]} .
\end{aligned}
$$

According to Jury's stability criterion, we put the $E_{1}, E_{2}, E_{3}$ values into the Jacobian matrix and obtain its characteristic roots which are greater than 1 , so $E_{1}, E_{2}, E_{3}$ are boundary equilibrium point.

Substitute the Nash equilibrium value $E_{4}$ into the Jacobian matrix and obtain the following:

$$
J\left(E_{4}\right)=\left(\begin{array}{cc}
1-0.45 k_{1} & 0 \\
0 & 1-0.4 k_{2}
\end{array}\right) .
$$

Characteristic equation is

$$
f(\lambda)=\lambda^{2}-B \lambda+C,
$$

where $B=2-0.4 k_{2}-0.45 k_{1}, C=1-0.45 k_{1}-0.4 k_{2}+0.18 k_{1} k_{2}$.

According to Jury's stability criterion, conditions (16) can be got which shows that the stability of the Nash equilibrium is determined by adjusting parameters $\left(k_{1}, k_{2}\right)$. Figure 8 shows the stability region when the system meets condition (16). As for the stability of the area, the system is gradually stable in local Nash equilibrium. $k_{1}<4.345, k_{2}<4.906$ is the stability domain where no matter how much initial value of manufacturers is, system (10) will be stable in Nash equilibrium after a finite time of gaming, and advertising stable range of manufacturers $A$ is not affected by that of manufacturer $B$. If $k_{1}, k_{2}$ are beyond the range of stability range, the system will change and evolve into chaotic state:

$$
\begin{aligned}
f(1) & =1-B+C>0, \\
f(-1) & =1+B+C>0, \\
f(0) & =C-1<0 .
\end{aligned}
$$

Based on the three conditions in (16), we can draw the figures to show the regions that satisfy each condition, as shown in Figure 6.

From Figure 6 we can see that the condition $f(1)>$ 0 always holds. The condition $f(-1)>0$ can hold when parameters $k_{1}$ and $k_{2}$ are in the same level, both small and big. The condition $f(0)<1$ can hold except when parameters $k_{1}$ 

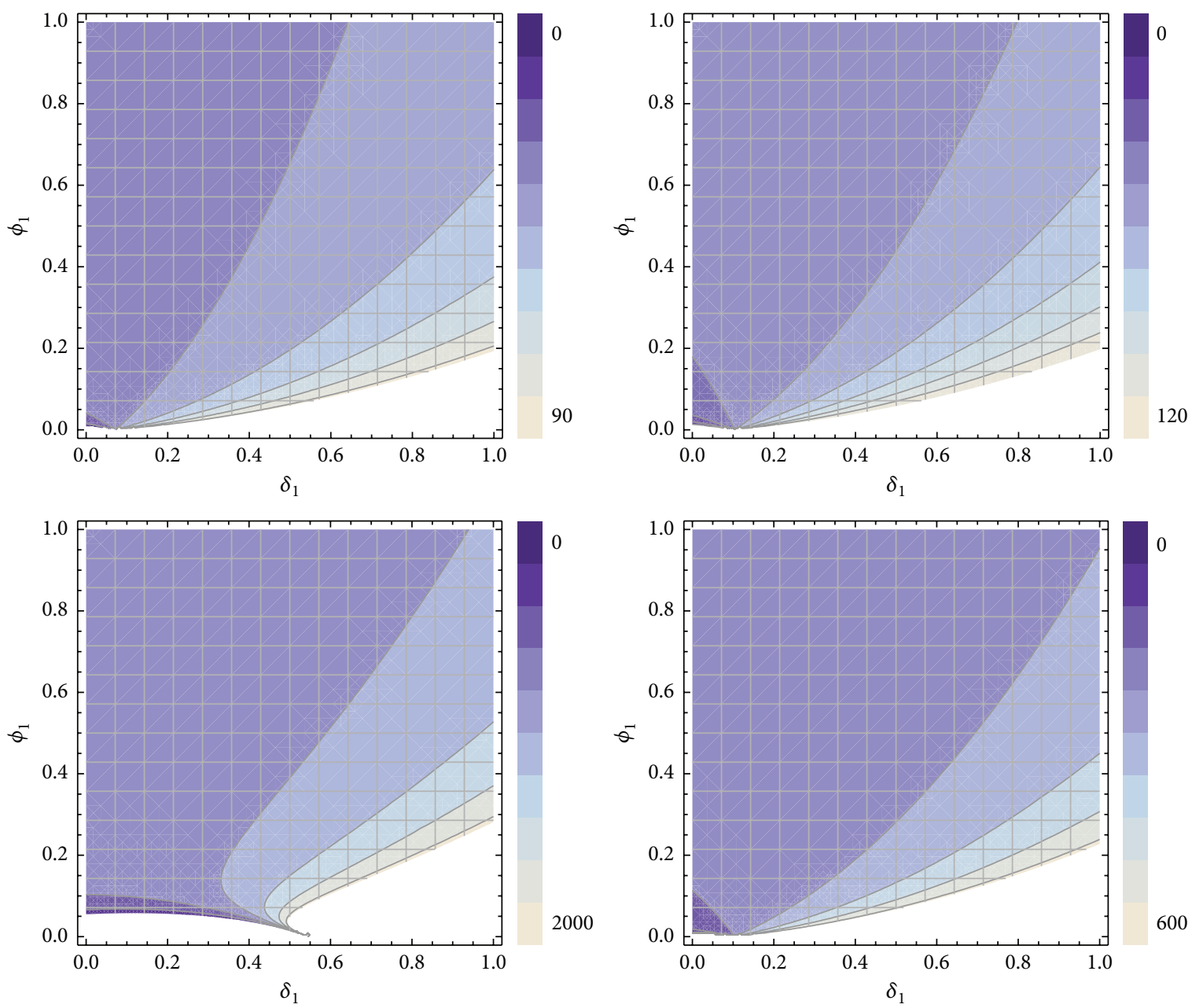

FIgURE 5: The influence of parameters $\delta_{1}$ and $\phi_{1}$ on $p_{1}, p_{2}$, and $A_{1}$ in decentralized decision making.

and $k_{2}$ are at high level. Above all, we can conclude that stable region will be that shown in Figure 7.

\subsubsection{The Influence of the Parameters on the System Stability.} In order to understand the influence of various parameters on the double channel supply chain, this section will simulate the complex dynamic behavior of supply chain using Matlab.

(1) The effect of adjustment factor $k_{1}, k_{2}$ on the stability of the double channel supply chain is as follows.

First of all, we analyze the effect of $k_{1}, k_{2}$ on the competition behavior of the system. Figure 9 shows the evolution of the advertising and retail price with the change of $k_{1}$ when $k_{2}=3$.

Figure 8 shows that when $k_{1}<4.345$, system (10) remains in stable state, while advertising and retail prices remain in $E_{4}=(4.365,3.536,32.37,4.365)$; when $k_{1}=4.345$, system $(10)$ appears for a two-period bifurcation and then system goes into two cycles, after four times for each cycle, and eightperiod-doubling bifurcation; then the final system entered into a state of chaos. Figure 10 shows the change of the corresponding maximum Lyapunov index, when the largest
Lyapunov exponent is equal to zero for the first time, system (10) occurs in the second period-doubling bifurcation; when the majority of Lyapunov indexes are greater than zero, system (10) evolves into chaotic state. Figure 11 shows the evolution of the advertising and retail price with the change of $k_{2}$ when $k_{1}=4$. Figure 11 shows that when $k_{2}<4.906$, system (10) remains in stable state, when $k_{2}=4.906$, system (10) appears in the first-time bifurcation; then system goes into the second-period, fourth-period, and eighth-period-doubling bifurcation and finally enters into chaos state. Figure 12 shows the changes of the corresponding maximum Lyapunov index. We can see that when the manufacturer's advertising adjusts too fast, the system may appear as chaos state.

Figure 13 shows the involution process of chaotic attractor of system (10) when the system is in stable state, two-period state, four-period state, and chaotic state. We find that even if system (10) is in chaos state, the behavior of the system is also attracted to be firmly fixed in one area which embodies the characteristics of the chaos-boundedness. Another key feature of the system in a chaotic state is the power spectrum of the system and the system's sensitivity to the initial value. Figures 8 and 9 show the power spectrum and the sensitive 

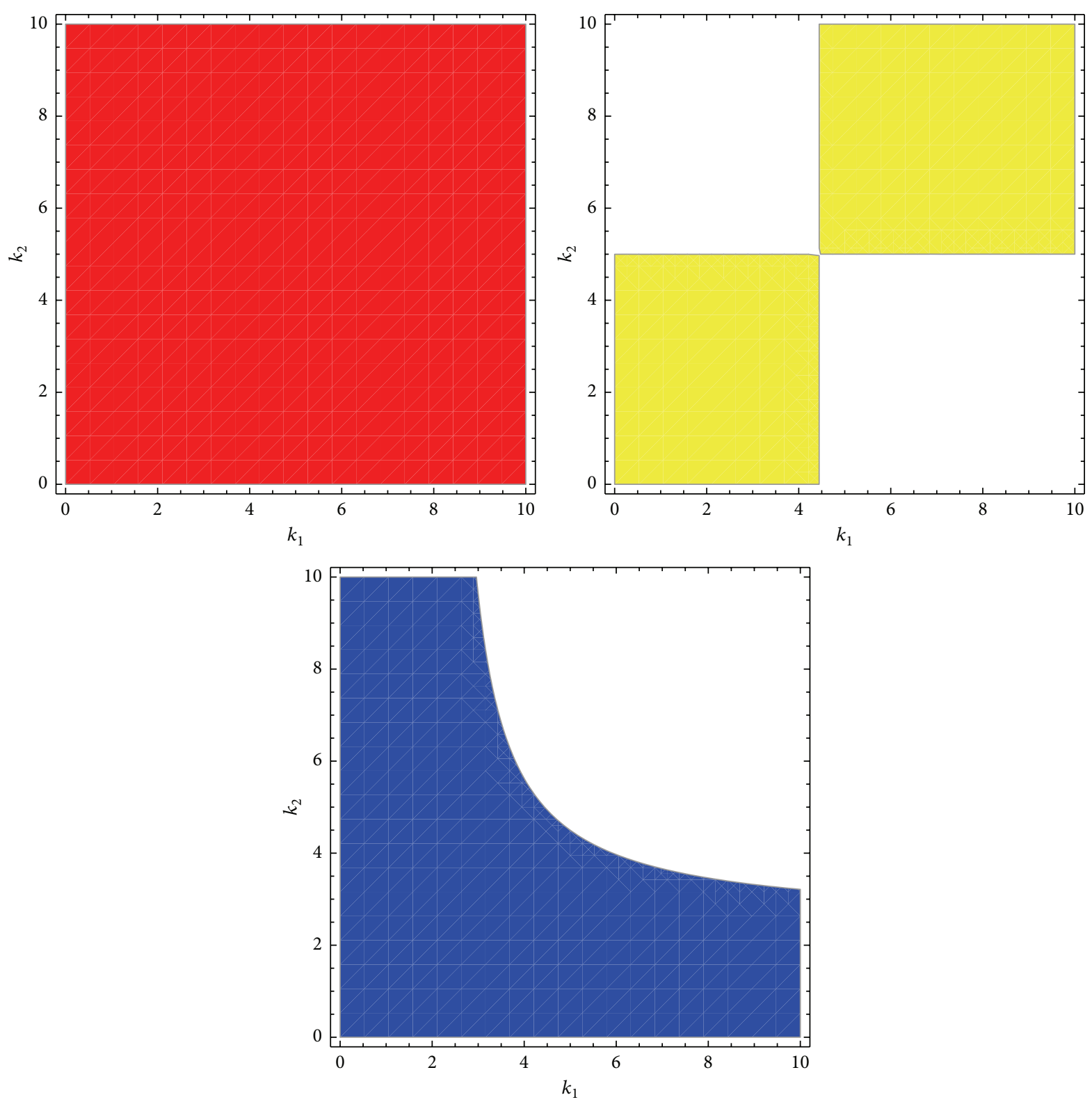

FIGURE 6: The regions satisfy the condition in (16).

dependence on initial value when system (10) is chaos state. We can see that system (10) shows the chaotic ergodicity characteristic in the process of evolution. Figure 14 shows the power spectrum of system (10). Figure 15 shows changes of the advertising and retail price when we set different initials $A_{1}=6$ and $A_{1}=6.001$, and we find that the result of the game will present a huge difference even if the difference between the initial prices was only 0.001 .

3.2.4. The Effect of Chaos Behavior on the Profit of the System. Figure 16 shows the profit bifurcation diagrams of manufacturers and retailers when changing $k_{1}$; it can be seen that if the system is in stable condition, after a finite game the system can be stable in the Nash equilibrium, then profit of each manufacturer or retailer is stable. If the market evolves from a stable state to a chaotic state, the profits of manufacturers and retailers will be in great fluctuation, which is not conducive for the manufacturers and the retailers to make decisions. Figure 17 shows the profits of manufacturers and retailers as the game cycle changes in different periods; we can see the profits of manufacturers and retailers are stable in the stable period; the profits of manufacturer and retailer appear as regular periodic fluctuation in the perioddoubling bifurcation period. When the system goes into chaos period, profits of manufacturers and retailers present chaotic fluctuations. So, manufacturers and retailers should maintain the stability of the system to avoid chaos.

Table 6 presents average profits of manufacturers and retailers in different periods. We can see that the average 




Figure 7: Stable region of system (10).



FIGURE 8: The parameter basin of system (10).

profit of manufacturers and retailers in stable period is more than the one in chaos period. The instability of system brings lots of losses to the manufacturers and retail profits. So manufacturers should make the system in stability state by adjusting the advertising investment.

\section{Chaos Control}

From the above analysis we can see that competitive advertising game makes the market equilibrium very short. There is wide variability in the market factors, such as adjusting speed of advertising, the uncertainty of customer demand, and the risk preference of retailers. If a manufacturer speeds up the adjustment advertising, market status will be changed and become unstable, even the state of chaos. Once the market evolved into chaotic state, each manufacturer cannot predict the future competition of the market, decisions will become disordered, and the market cannot reach equilibrium. The above analysis shows that profits of manufacturers and retailers in the unstable cycle are less than the one in stable period. However, excessive advertising may easily cause the market failure and disorder, resulting in loss of profits at the same time. Therefore, using some control method making the system back to the stable equilibrium is very important.

This section uses delay feedback control (DFC) to control the system chaos. The main idea of this method is to make 



- $A_{1}$

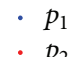

FIGURE 9: The bifurcation diagram of advertising and retail prices with the change of $k_{1}$ when $k_{2}=3$.

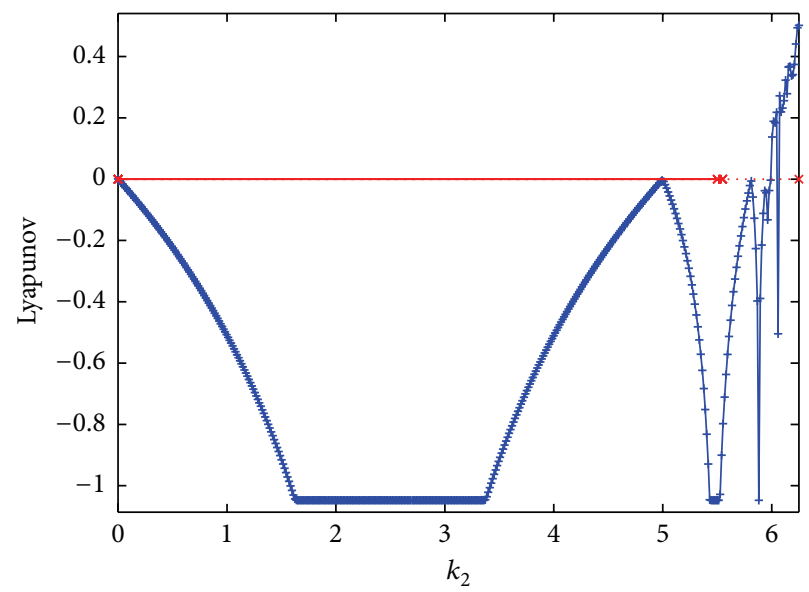

FIGURE 10: With the change of parameters $k_{1}$ system with corresponding Lyapunov (10).


- $A_{1}$

- $A_{2}$

- $p_{1}$

- $p_{2}$

FIGURE 11: The bifurcation diagram of advertising and retail prices with the change of $k_{2}$ when $k_{1}=4$. 


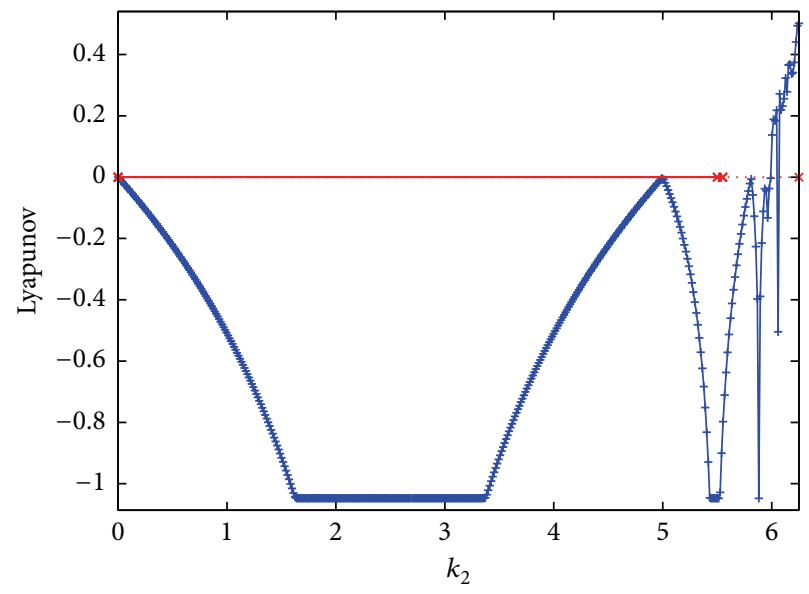

FIGURE 12: With the change of parameters $k_{2}$ system with corresponding Lyapunov (10).

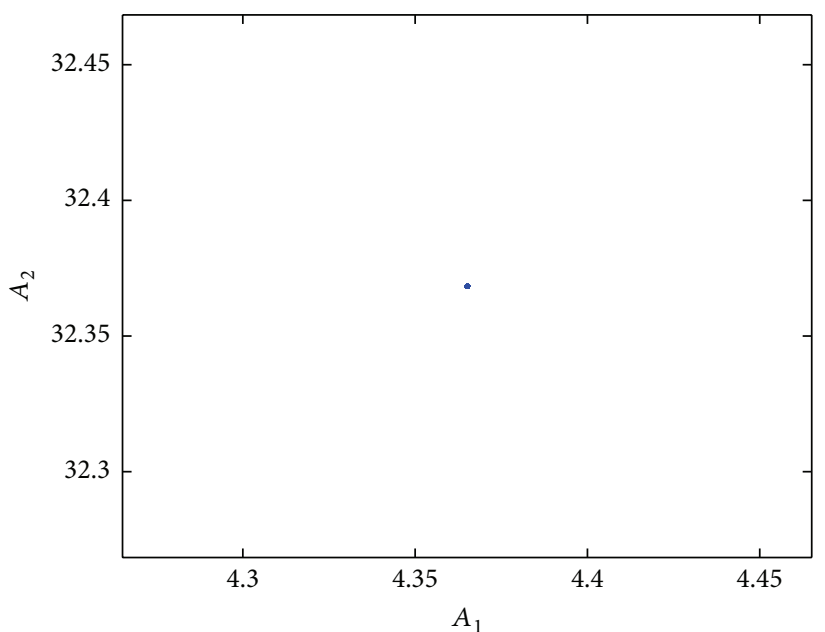

(a)



(c)



(b)

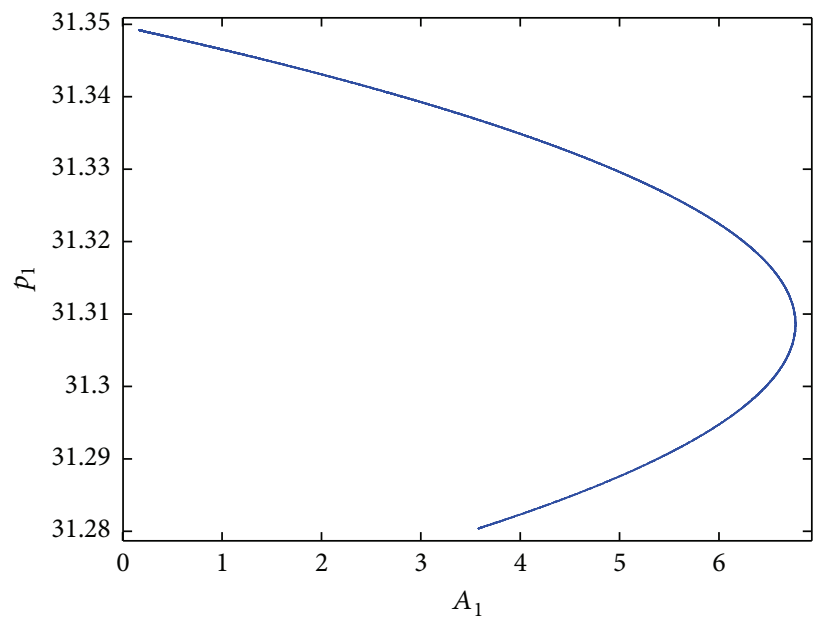

(d)

FIGURE 13: The chaotic attractor of system (10). 




$\multimap A_{1}$

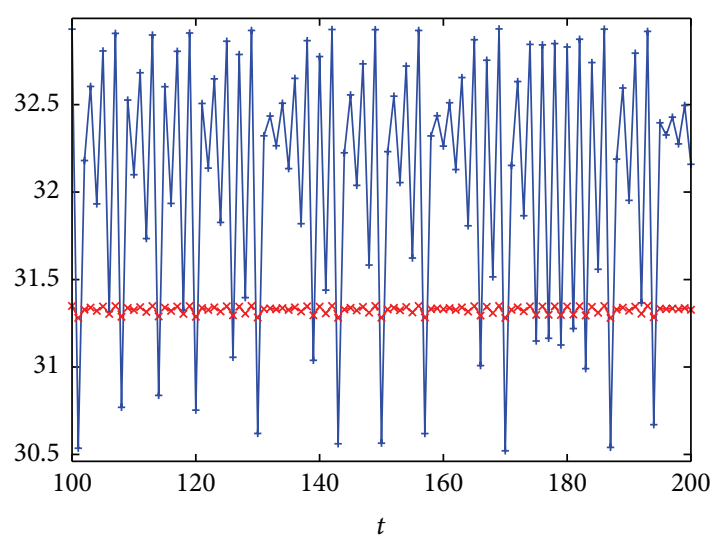

$+p_{1}$

(a) Advertising

(b) The retail price

Figure 14: The power spectrum of system (10).

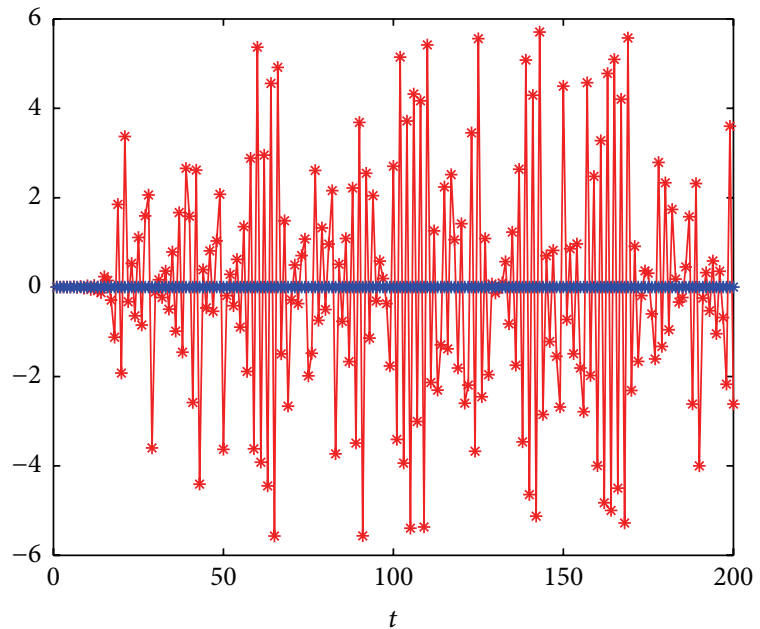

* $A_{1}$



* $p_{1}$

(a) Advertising

(b) The retail price

FIgURE 15: The sensitivity to initial value when $k_{1}=5.5, k_{2}=3$.

the system become stable using the system output signal and the input signal from the feedback coupling between the control signals, $x(t+1)=f(x(t))+u(t+1), u(t+1)=$ $K(x(t+1)-x(t-1-\tau)), t>\tau$. $\tau$ is delay time; $K$ is regulating factor. In this section we only make delay feedback control of $A_{1}$ and can make all the variables in the system to reach steady state. By joining delay feedback control into the advertising game equation of $M_{1}$, we can obtain

$$
\begin{aligned}
A_{1}(t+1)= & A_{1}(t)+k_{1} A_{1}(t)\left(\frac{w_{1}\left(\theta R_{R_{1}}+\sigma_{1}^{2}\right)\left[R_{R_{2}}\left(-b \beta+2 \alpha \theta+2 \theta \delta_{1}\right)+\sigma_{2}^{2}\left(\alpha+\delta_{1}\right)\right]}{2 \sqrt{A_{1}(t)}\left(\sigma_{1}^{2}\left(2 \theta R_{R_{2}}+\sigma_{2}^{2}\right)+R_{R_{1}}\left(2 \theta \sigma_{2}^{2}-R_{R_{2}}\left(b^{2}-4 \theta^{2}\right)\right)\right)}-\phi_{1}\right) \\
& -K\left(A_{1}(t+1)-A_{1}(t+1-\tau)\right), \\
A_{2}(t+1)= & A_{2}(t)+k_{2} A_{2}(t)\left(\frac{w_{2}\left(\theta R_{R_{2}}+\sigma_{2}^{2}\right)\left[R_{R_{1}}\left(b \beta-2 \alpha \theta-2 \theta \delta_{2}\right)-\sigma_{1}^{2}\left(\alpha+\delta_{2}\right)\right]}{2 \sqrt{A_{2}(t)}\left(-\sigma_{1}^{2}\left(2 \theta R_{R_{2}}+\sigma_{2}^{2}\right)+R_{R_{1}}\left(\left(b^{2}-4 \theta^{2}\right) R_{R_{2}}-2 \theta \sigma_{2}^{2}\right)\right)}-\phi_{2}\right) .
\end{aligned}
$$




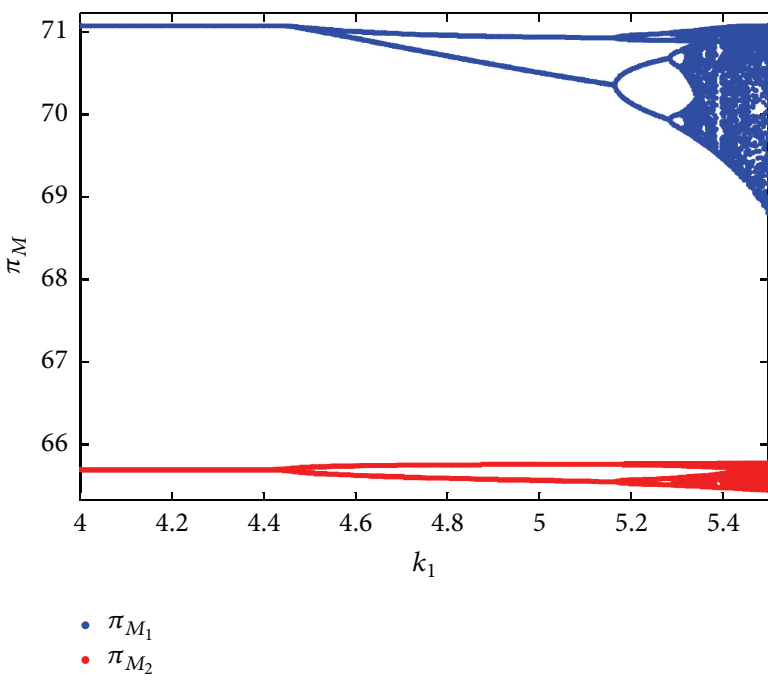

(a)

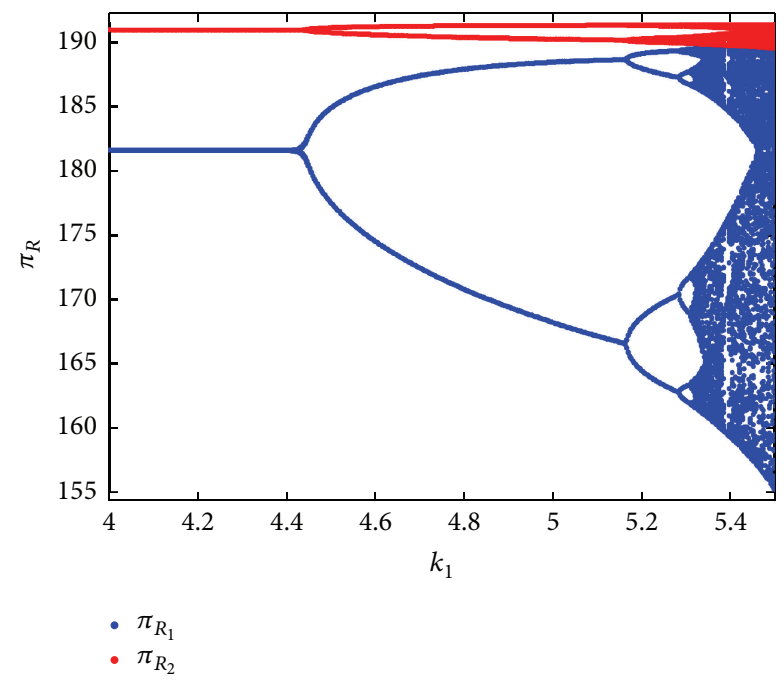

(b)

FIGURE 16: The bifurcations of profit with the change of $k_{1}$ when $k_{2}=3$.

TABLE 6: The average profit of system (10) at different period.

\begin{tabular}{lccc}
\hline Profit & Stable period & $\begin{array}{c}\text { Different state } \\
\text { 2-period state }\end{array}$ & $\begin{array}{c}\text { Chaotic state } \\
\end{array}$ \\
$k_{1}=4, k_{2}=3$ & $k_{1}=5, k_{2}=3$ & $k_{1}=5.5, k_{2}=3$ \\
\hline$\pi_{M_{1}}$ & 72.5 & 72.07 & 72.12 \\
$\pi_{M_{2}}$ & 60.95 & 60.93 & 60.93 \\
$\pi_{R_{1}}$ & 160.1 & 156.79 & 157.22 \\
$\pi_{R_{2}}$ & 174 & 173.72 & 173.73 \\
\hline
\end{tabular}

From the above analysis, we know that when $k_{1}=$ $5.5, k_{2}=3$, system (10) is in a chaotic state. Next, we mainly control dual-channel supply chain system (17) considering $\tau=1$. Joining delay control system (17) into the Jacobin matrix we have

$$
\begin{aligned}
& J(E) \\
& =\left(\begin{array}{cc}
\frac{\left(1+K-k_{1} \phi_{1}+k_{1} w_{1} H_{1}\right)}{(1+K)} & 0 \\
0 & 1-k_{2} \phi_{2}+k_{2} w_{2} H_{2}
\end{array}\right),
\end{aligned}
$$

where $H_{1}, H_{2}$ are, as previously shown, the value of the parameter and the Nash equilibrium to formula (18). We can obtain characteristic root of system (17), $\lambda_{1}=-0.2, \lambda_{2}=$ $(K-1.475) /(K+1)$. Because $|(K-1.475) /(K+1)|<1$ obtains $K>0.2375$, system (17) is in a stable state.

Figure 18 is the bifurcation diagrams of $A_{1}$ and $A_{2}$ with the change of $K$. With the increase of $K, A_{1}$ and $A_{2}$ gradually change from the chaotic state to steady state. When $K=$ $0.2375, A_{1}$ and $A_{2}$ are finally stable in Nash equilibrium $(4.365,4.365)$. In order to have more detailed understanding of the behavior of the system under different $K$ values, we take different values of $K$. Figure 19 simulates the process of evolution. When $K=0.15$, system (17) is in the second cycle state, and when $K=0.35$, system (17) is in a stable state. So, delayed feedback control method can control the system well and make the system back to a stable state.

\section{Conclusion}

In this paper, we develop a dual-channel supply chain competition model including two manufacturers and two retailers. Manufacturers who consider advertising as a decision variable have overconfidence behavior; the retailers adjust their decisions according to the retail price of the product and are rick oriented. All of these make the double channel supply chain more complex; thus the decentralized decision making model and the Stackelberg decision making model are introduced. We find that under the master-slave game model the profits of manufacturers are greater than those under decentralized decision-making mode, and the profits of retailers under master-slave game model are less than those under decentralized decision-making mode. Using the method of nonlinear dynamics, system stability is analyzed, and the analysis demonstrates the complex behavior of the supply chain using the bifurcation diagram, the attractor, maximum Lyapunov index and sensitivity to the initial value, and so forth. Price adjustment speed has an important influence on the stability of dynamic evolutionary game model and Delay Feedback Control Method can effectively control the chaotic behavior of dual-channel supply chain model.

\section{Competing Interests}

We declare that there are no competing interests regarding the publication of this paper. 

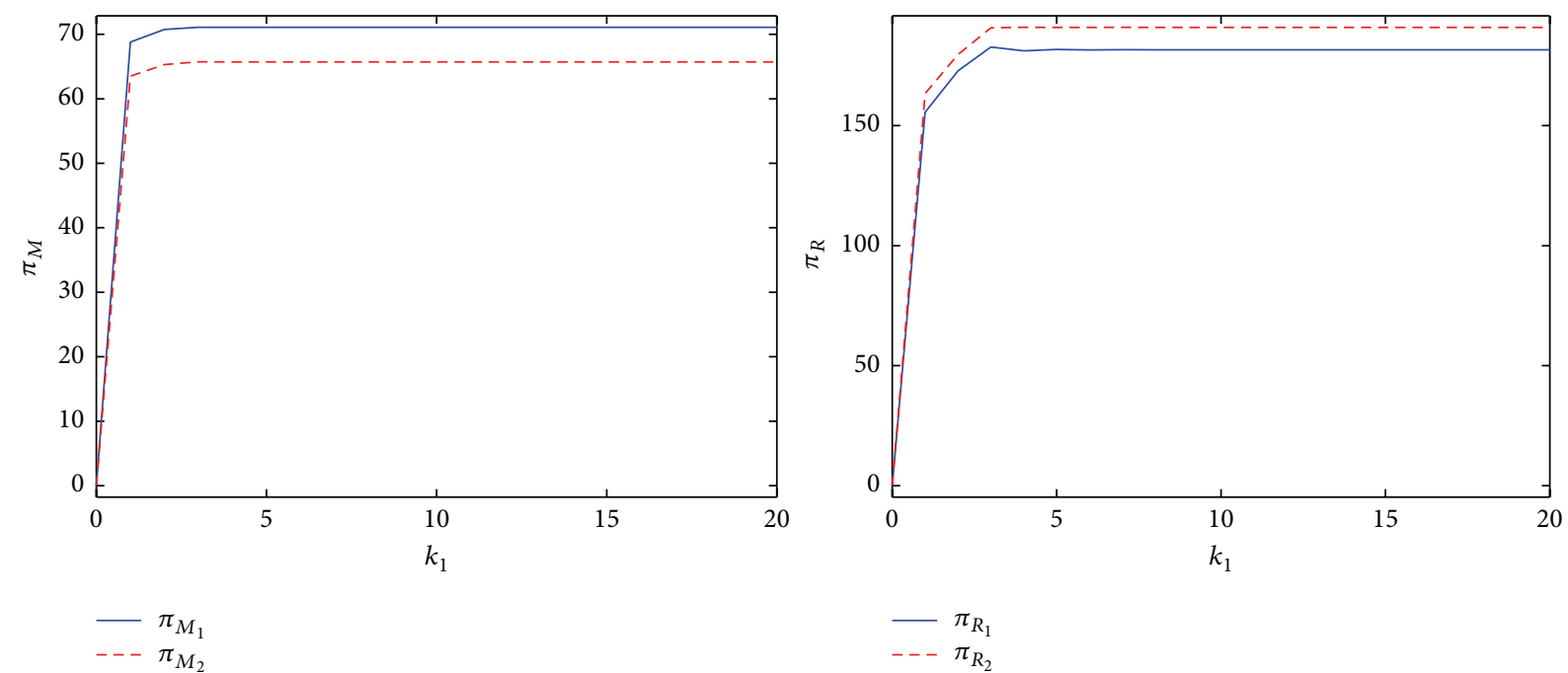

(a) Stable state
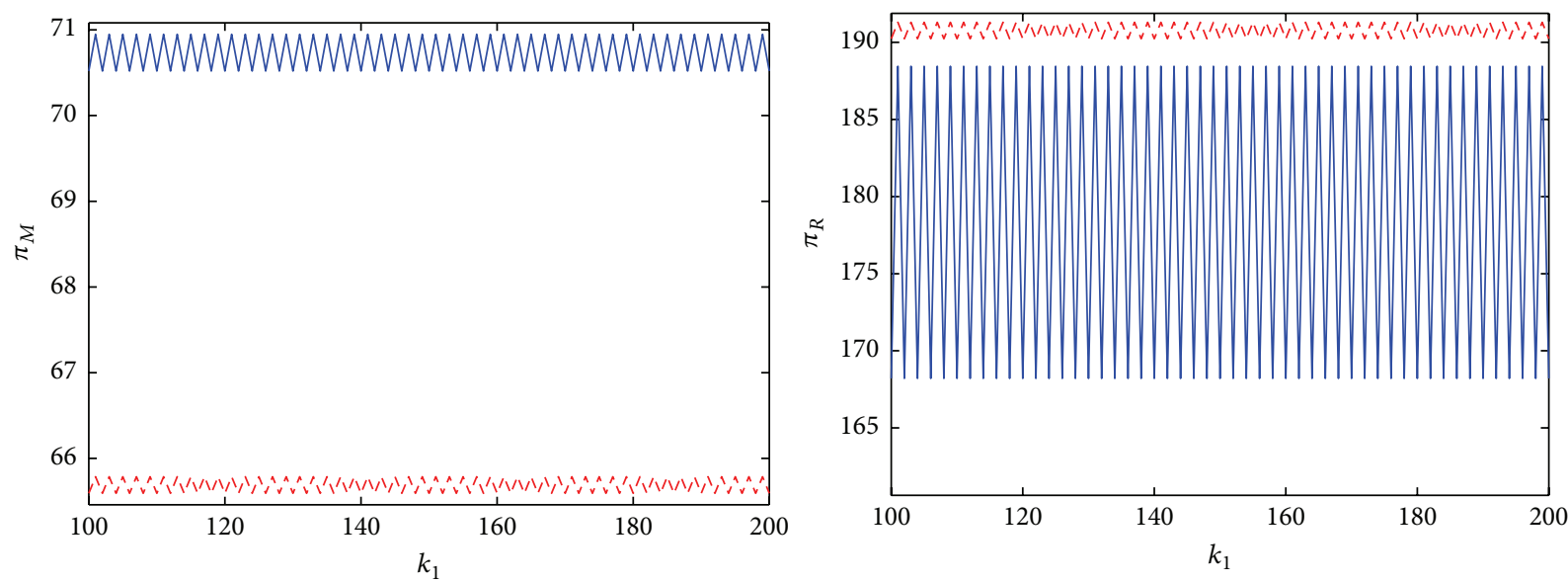

$-\pi_{M_{1}}$

$\begin{array}{ll}- & \pi_{R_{1}} \\ --- & \pi_{R_{2}}\end{array}$

(b) 2-period state


$\begin{array}{ll}- & \pi_{M_{1}} \\ --- & \pi_{M_{2}}\end{array}$

$\begin{array}{ll}- & \pi_{R_{1}} \\ --- & \pi_{R_{2}}\end{array}$

(c) Chaotic state

FIGURE 17: The profits of manufacturers and retailers in different periods of change. 


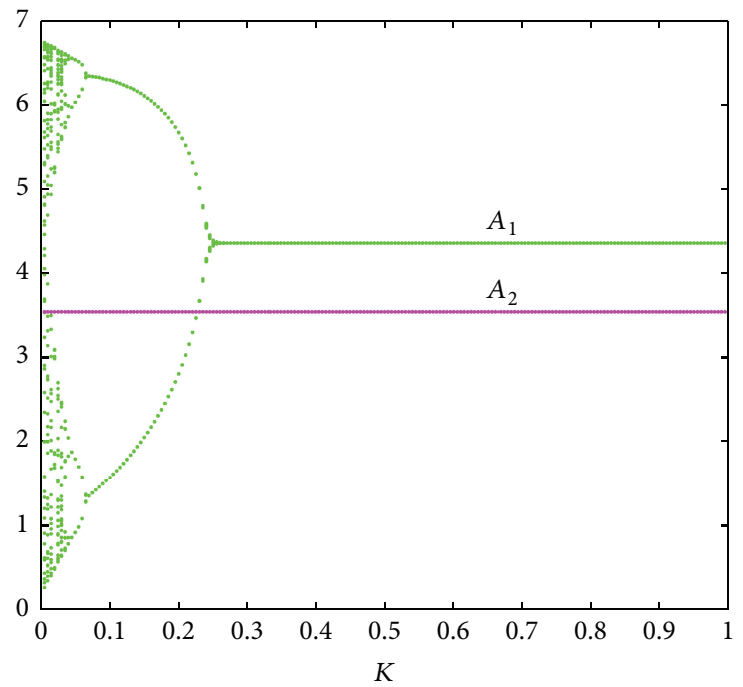

FIgURE 18: The bifurcation diagrams $A_{1}$ and $A_{2}$ with the change of $K$.

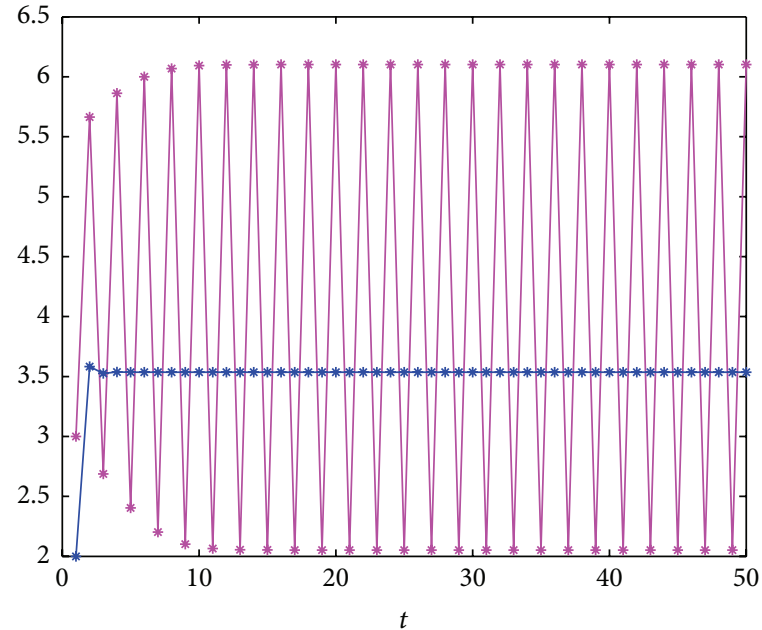

$\begin{array}{ll}\rightarrow & A_{1} \\ \rightarrow & A_{2}\end{array}$



* $A_{1}$

(a) $K=0.15$

(b) $K=0.35$

FIgURE 19: When $K$ is different, $A_{1}$ and $A_{2}$ game process over time.

\section{Acknowledgments}

The research was supported by the National Natural Science Foundation of China (nos. 71571131 and 61273231), Doctoral Fund of Ministry of Education of China (Grant no. 20130032110073), and Tianjin University Innovation Fund.

\section{References}

[1] S. Karray, "Periodicity of pricing and marketing efforts in a distribution channel," European Journal of Operational Research, vol. 228, no. 3, pp. 635-647, 2013.

[2] X. He, A. Prasad, and S. P. Sethi, "Cooperative advertising and pricing in a dynamic stochastic supply chain: feedback stackelberg strategies," Production and Operations Management, vol. 18, no. 1, pp. 78-94, 2009.

[3] P. De Giovanni, "Quality improvement vs. advertising support: which strategy works better for a manufacturer?" European Journal of Operational Research, vol. 208, no. 2, pp. 119-130, 2011.

[4] J. Zhang, Q. Gou, L. Liang, and Z. Huang, "Supply chain coordination through cooperative advertising with reference price effect," Omega, vol. 41, no. 2, pp. 345-353, 2013.

[5] B. Liu, G. S. Cai, and A. A. Tsay, "Advertising in asymmetric competing supply chains," Production and Operations Management, vol. 23, no. 11, pp. 1845-1858, 2014.

[6] R. Zhang, B. Liu, and W. L. Wang, "Pricing decisions in a dual channels system with different power structures," Economic Modelling, vol. 29, no. 2, pp. 523-533, 2012. 
[7] S. Alaei, R. Alaei, and P. Salimi, "A game theoretical study of cooperative advertising in a single-manufacturer-two-retailers supply chain," International Journal of Advanced Manufacturing Technology, vol. 74, no. 1-4, pp. 101-111, 2014.

[8] A. Ahmadi Javid and P. Hoseinpour, "A game-theoretic analysis for coordinating cooperative advertising in a supply chain," Journal of Optimization Theory and Applications, vol. 149, no. 1, pp. 138-150, 2011.

[9] W. Q. Zhang, S. L. Li, D. Zhang, and W. Hou, "On the impact of advertising initiatives in supply chains," European Journal of Operational Research, vol. 234, no. 1, pp. 99-107, 2014.

[10] R. X. Guo, H. Lee, and R. Swinney, "The impact of supply chain structure on responsible sourcing," Working Paper, 2013.

[11] B. C. Giri and S. Sharma, "Manufacturer's pricing strategy in a two-level supply chain with competing retailers and advertising cost dependent demand," Economic Modelling, vol. 38, pp. 102111, 2014.

[12] S. Jorgensen, S. Taboubi, and G. Zaccour, "Retail promotions with negative brand image effects: is cooperation possible?" European Journal of Operational Research, vol. 150, no. 2, pp. 395-405, 2003.

[13] S. Jørgensen, S. P. Sigué, and G. Zaccour, "Dynamic cooperative advertising in a channel," Journal of Retailing, vol. 76, no. 1, pp. 71-92, 2000.

[14] X. He, A. Krishnamoorthy, A. Prasad, and S. P. Sethi, "Co-op advertising in dynamic retail oligopolies," Decision Sciences, vol. 43, no. 1, pp. 73-106, 2012.

[15] Z. Huang and S. X. Li, "Co-op advertising models in manufacturer-retailer supply chains: a game theory approach," European Journal of Operational Research, vol. 135, no. 3, pp. 527-544, 2001.

[16] J. Yue, J. Austin, M.-C. Wang, and Z. Huang, "Coordination of cooperative advertising in a two-level supply chain when manufacturer offers discount," European Journal of Operational Research, vol. 168, no. 1, pp. 65-85, 2006.

[17] S. Karray and G. Zaccour, "Could co-op advertising be a manufacturer's counterstrategy to store brands?" Journal of Business Research, vol. 59, no. 9, pp. 1008-1015, 2006.

[18] S. Karray and G. Zaccour, "Effectiveness of coop advertising programs in competitive distribution channels," International Game Theory Review, vol. 9, no. 2, pp. 151-167, 2007.

[19] A. Chutani and S. P. Sethi, "Optimal advertising and pricing in a dynamic durable goods supply chain," Journal of Optimization Theory and Applications, vol. 154, no. 2, pp. 615-643, 2012.

[20] J. H. Ma and Q. X. Li, "The complex dynamics of BertrandStackelberg pricing models in a risk-averse supply chain," Discrete Dynamics in Nature and Society, vol. 2014, Article ID 749769, 14 pages, 2014.

[21] B. Li, P. Chen, Q. Li, and W. Wang, "Dual-channel supply chain pricing decisions with a risk-averse retailer," International Journal of Production Research, vol. 52, no. 23, pp. 7132-7147, 2014.

[22] P. Zhang, Y. Xiong, and Z. K. Xiong, "Coordination of a dual-channel supply chain after demand or production cost disruptions," International Journal of Production Research, vol. 53, no. 10, pp. 3141-3160, 2015.

[23] S. Panda, N. M. Modak, S. S. Sana, and M. Basu, "Pricing and replenishment policies in dual-channel supply chain under continuous unit cost decrease," Applied Mathematics and Computation, vol. 256, pp. 913-929, 2015.
[24] T. Li, J. Ma, and L. Sun, "Complexity uncertainty analysis of dynamic in a dual-channel energy supply chain model with heterogeneous retailers," Mathematical Problems in Engineering, Article ID 562158, Art. ID 562158, 10 pages, 2015.

[25] J. Ma and Z. Guo, "Research on the complex dynamic characteristics and RLS estimation's influence based on price and service game," Mathematical Problems in Engineering, vol. 2015, Article ID 302506, 13 pages, 2015.

[26] L. Sun and J. Ma, "Study and simulation on discrete dynamics of Bertrand triopoly team-game," Mathematical Problems in Engineering, vol. 2015, Article ID 960380, 12 pages, 2015. 


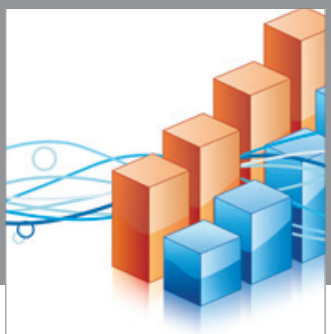

Advances in

Operations Research

vatem alat4

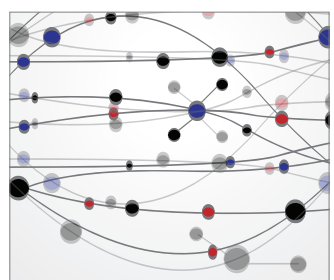

\section{The Scientific} World Journal

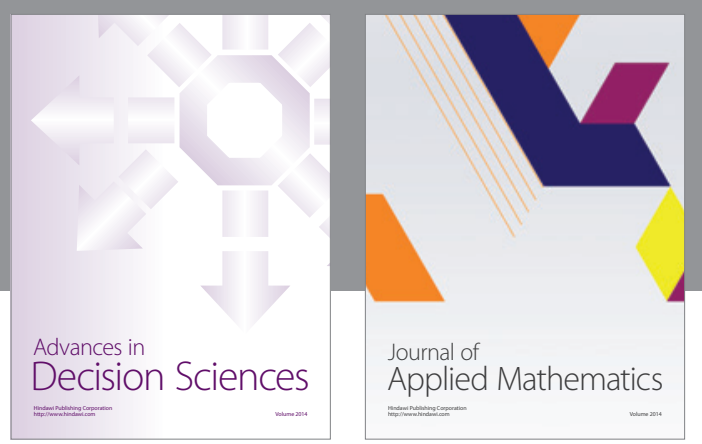

Algebra

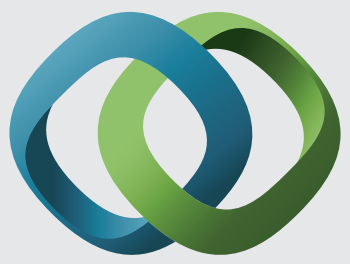

\section{Hindawi}

Submit your manuscripts at

http://www.hindawi.com
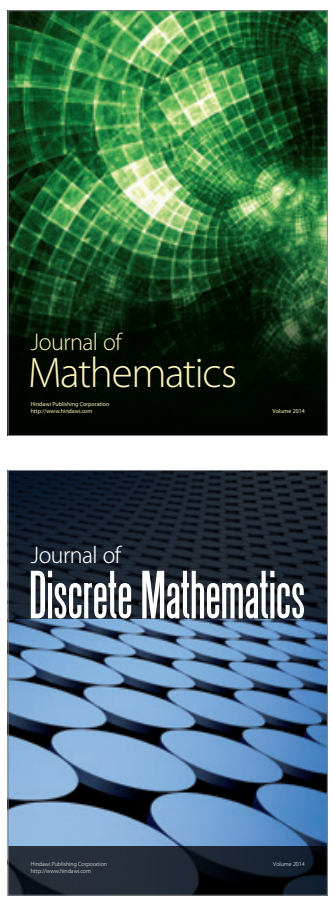

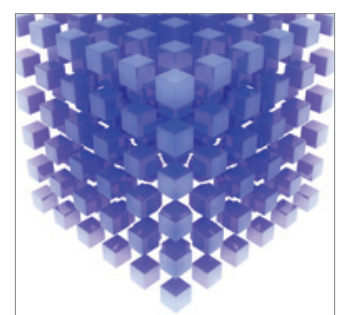

Mathematical Problems in Engineering


Journal of

Function Spaces

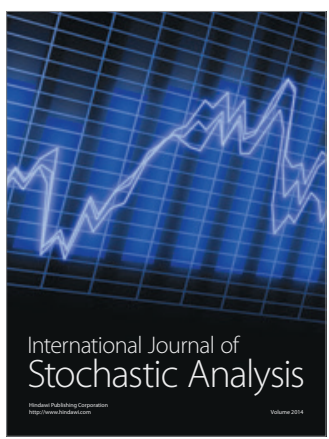


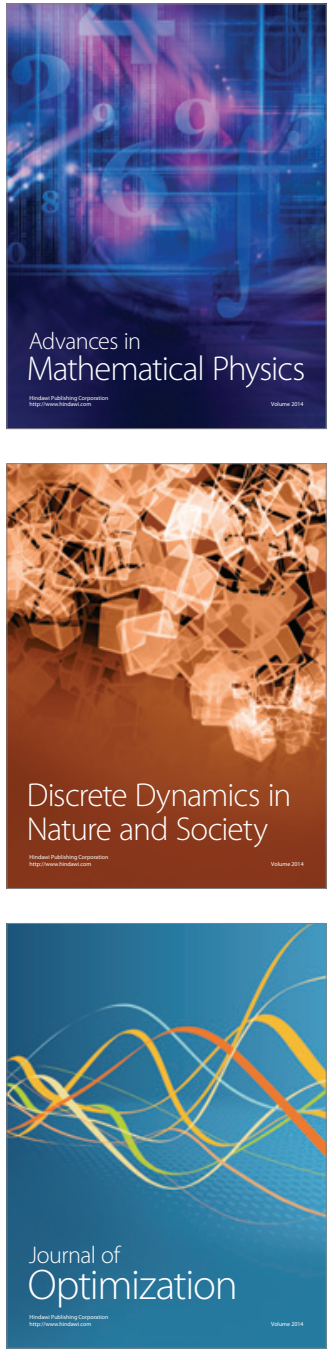